\title{
Peningkatan Kapasitas Dosen dan Mahasiswa dalam Pemanfaatan Software Lisrel di STT Renatus Pematang Siantar
}

\author{
Sihar Tambun \\ Program Studi Akuntasi, Fakultas Ekonomi dan Bisnis, Universitas 17 Agustus 1945 Jakarta, Indonesia \\ Email: sihar.tambun@gmail.com
}

\begin{abstract}
The purpose of implementing this community service program was to improve the ability of lecturers and students in processing research data using Lisrel software. This activity was carried out through three stages, namely the planning stage, the implementation stage and the evaluation stage. The method used are lecture method and practice. The resource person who became the instructor in this training was a lecturer at the 17 Augustus 1945 Jakarta University as a form of community service. This training was very much needed at STT Renatus Pematang Siantar because there were no lecturers and students who have mastered the use of this software properly. The results of the evaluation were carried out by comparing the pretest and posttest scores. There was an increase in the mastery of software in the majority of the trainees. The majority of participants already understand well how to input data, how to process data and how to interpret the results of data processing. It is hoped that the participants will continue to learn and practice their skills in processing research data with Lisrel software, so that these skills can support the careers of the participants and support the performance of their institutions.
\end{abstract}

Keywords: Lecturer Capacity, Student Capacity, Data Processing, Lisrel Software.

\begin{abstract}
Abstrak
Tujuan pelaksanaan program pengabdian kepada masyarakat ini adalah untuk meningkatkan kemampuan para dosen dan mahasiswa dalam pengolahan data penelitian menggunakan software Lisrel. Kegiatan ini dilaksanakan melalui tiga tahapan, yaitu tahapan perencanaan, tahapan pelaksanaan dan tahapan evaluasi. Metode yang dipergunakan dalam program ini adalah metode ceramah dan praktek. Narasumber yang menjadi instruktur dalam pelatihan ini adalah dosen Universitas 17 Agustus 1945 Jakarta sebagai wujud pengabdian kepada masyarakat. Pelatihan ini sangat dibutuhkan di STT Renatus Pematang Siantar karena belum ada dosen dan mahasiswa yang menguasai pemanfaatan software ini dengan baik. Hasil evaluasi dilakukan dengan membandingkan score pretest dan score posttest. Terjadi peningkatan penguasaan software pada mayoritas peserta pelatihan. Mayoritas peserta sudah memahami dengan baik cara input data, cara mengolah data dan cara interpretasi hasil pengolahan data. Harapan kepada para peserta agar terus belajar dan melatih keahlian mengolah data penelitian dengan software lisrel, sehingga keahlian ini dapat menunjang karir para peserta dan mendukung kinerja institusinya.
\end{abstract}

Kata Kunci: Kapasitas Dosen, Kapasitas Mahasiswa, Pengolahan Data, Software Lisrel.

\section{A. PENDAhuluan}

Kinerja penelitian dari para dosen dan mahasiswa sangat dibutuhkan untuk mendukung kinerja institusi. Hasil penelitian disajikan dalam bentuk artikel dan dipublikasi. Bila para dosen atau mahasiswa bisa mempublikasikan hasil penelitiannya di jurnal nasional dan internasional terindeks bereputasi akan memperoleh score yang tinggi (Win et al., 2020). Score tersebut akan menjadi point yang besar untuk kinerja institusi, untuk penilaian akreditasi dan untuk persyaratan kenaikan jabatan akademik para dosen (Retnowati et al., 2018). Untuk menghasilkan satu artikel penelitian yang baik dibutuhkan kemampuan dalam mengolah data hasil penelitian, khususnya dalam riset kuantitatif (Powell, 2020). Salah satu software yang sering digunakan untuk menguji model penelitian dan hipotesis adalah software lisrel (Molenaar, 2019). Software ini dapat digunakan untuk menguji kriteria data dengan confirmatory factor analysis, goodness of fit dan pengujian hipotesis berbagai model (Ondé \& Alvarado, 2018). Saat ini belum ada dosen dan mahasiswa di STT Renatus Pematang Siantar yang mahir menggunakan software lisrel untuk pengolahan data penelitian kuantitatif. 
Kinerja penelitian dosen dan mahasiswa di STT Renatus Pematang Siantar hingga tahun 2021 masih belum maksimal. Belum banyak dosen yang berhasil mempublikasikan hasil penelitiannya di jurnal nasional dan internasional bereputasi. Potensi sumber daya manusia di institusi sangat banyak karena memiliki dosen pada program studi sarjana, pasca sarjana dan program studi doktor. Salah satu kendala yang dihadapi adalah kesulitan untuk membuat artikel yang berkualitas, kususnya artikel penelitian dari riset kuantitatif. Belum ada dosen yang mampu menguji model penelitian structural equation modelling dengan menggunakan software lisrel. Baik untuk input data, mengolah data dan interpretasi hasil pengolahan data. Demikian juga para mahasiswa di program sarjana hingga program doktoral, belum ada yang menguasai software lisrel. Dibutuhkan pelatihan yang bisa memandu mereka untuk bisa mandiri mengolah data penelitian dengan menggunakan software lisrel.

Tujuan dari kegiatan pengabdian kepada masyarakat ini adalah untuk memberikan edukasi dan pelatihan kepada dosen dan mahasiswa di STT Renatus Pematang Siantar. Edukasi ini dilakukan untuk menambah kemampuan dosen dan mahasiswa dalam pengolahan data menggunakan software lisrel. Kemampuan yang diharapkan akan dimiliki para peserta mulai dari penguasaan proses input data ke lisrel, penguasaan uji confirmatory factor analysis dan goodness of fit dengan software lisrel, serta pengujian berbagai model hipotesis dengan menggunakan software lisrel. Luaran dari kegiatan pengabdian kepada masyarakat ini diharapkan dapat berdampak besar pada peserta. Peserta mampu secara mandiri menggunakan software lisrel, mulai dari cara input data, cara menguji kualitas data, cara menguji hipotesis penelitian dan interpretasi hasil penelitian. Kemampuan ini diharapkan akan meningkatkan kualitas penelitian para dosen dan mahasiswa.

\section{B. PELAKSAAN DAN METODE}

Pelatihan adalah salah satu cara yang dapat dipergunakan untuk meningkatkan kemampuan, pengetahuan dan kompetensi seseorang menjadi lebih baik (Burn et al., 2019). Kegiatan pelatihan ini adalah bentuk pengabdian kepada masyarakat agar para peserta mampu secara mandiri menggunakan software lisrel sehingga dapat meningkatkan kualitas penelitian dosen dan mahasiswa. Pelatihan dilaksanakan melalui tiga tahapan. Pertama, tahapan perencanaan kegiatan pengabdian kepada masyarakat. Pada tahapan ini panitia berkomunikasi dengan pimpinan STT Renatus Pematang Siantar. Komunikasi bertujuan untuk menginformasikan rencana pelaksanaan kegiatan pengabdian kepada masyarakat. Komunikasi ini dilakukan oleh dosen dan tim yang tergabung dalam kepanitiaan program pengabdian kepada masyarakat. Komunikasi dengan pihak pimpinan STT Renatus Pematang Siantar juga bertujuan untuk membicarakan permasalahan yang dihadapi dan materi pelatihan yang akan diberikan. Dari identifikasi permasalahan yang ada, permasalahan diurutkan berdasarkan urgensi dan prioritas kebutuhan dosen dan mahasiswa. Berdasarkan hasil diskusi panitia dengan pimpinan STT Renatus Pematang Siantar, maka disepakati kegiatan yang dilakukan adalah pelatihan. Pelatihan diadakan bertujuan untuk mengedukasi para peserta sehingga mampu secara mandiri mengolah data penelitian dengan menggunakan software lisrel. Kepada pihak pimpnan STT Renatus Pematang Siantar dimintakan ijin untuk pelaksanaan kegiatan. Panitia juga mengajukan waktu pelaksanaan, tempat dan kebutuhan peralatan untuk mendukung pelaksanaan acara tersebut. Kedua, tahapan pelaksanaan. Program pengabdian kepada masyarakat ini dilaksanakan di gedung STT Renatus Pematang Siantar. Dilaksanakan pada tanggal 5 Januari 2022. Pelaksanaan dilakukan secara tatap muka dengan menjalankan protokol kesehatan. Tahapan pelaksanaan dimulai dari sambutan dan pembukaan acara dari pimpinan STT Renatus Pematang Siantar. Selanjutnya ceramah dari dosen sebagai pemateri di acara ini. Materi disampaikan adalah teori dan praktek penggunaan software lisrel untuk pengolahan data penelitian kuantitatif. Para peserta juga diberikan fasalitas software lisrel dan diinstal ke laptop masing-masing. Selanjutnya para peserta diajarkan praktek cara input data, praktek cara uji kualitas data dengan confirmatory factor analysis dan goodness of fit dan praktek cara pembuktian hipotesis dengan software lisrel. Ketiga, tahapan evaluasi. Tujuan dari evaluasi untuk mengetahui tingkat penerimaan dari para peserta, sekaligus untuk mengetahui tingkat keberhasilan pelatihan yang dilakukan (Bliss et al., 2021). Instrumen yang digunakan dalam evaluasi dan monitoring adalah pertanyaan di pretest dan posttest. Instrumen lainnya adalah meminta pendapat dari para peserta terkait keunggulan dan kelemahan dari kegiatan tersebut, serta saran mereka untuk kegaitan-kegiatan selanjutnya. Pelaksanaan pretest dan posttest relevan dilakukan untuk mengetahui peningkatan pemahaman atau kemampuan peserta terkait dengan topik pelatihan yang telah diikuti peserta. Hasil score pretest dan posttest dibandingkan untuk mengetahui peningkatan pemahaman dan kemampuan para peserta.

Metode yang digunakan dalam pelatihan ini adalah metode ceramah dan praktek. Ceramah dilakukan untuk menyampaikan materi tentang pengenalan tools dan fasilitas yang ada di dalam software lisrel. Metode praktek dilakukan agar peserta memiliki pengalaman simulasi penggunaan software lisrel dari awal hingga akhir. Pengalaman praktek sangat efektif dalam mempelajari sebuah software pengolahan data. Selain itu, diskusi juga dilakukan untuk mendapatkan feedback dari para peserta, 
sehingga diketahui sejauh mana pererimaan para peserta pada materi yang telah disampaikan (Ying, 2020). Metode diskusi dilakukan agar para peserta juga aktif dalam kegiatan pelatihan tersebut.

\section{HASIL DAN PEMBAHASAN}

Pelaksanaan kegiatan program pengabdian kepada masyarakat ini berjalan sesuai dengan yang direncanakan. Acara dibuka oleh pimpinan STT Renatus Pematang Siantar. Jumlah peserta yang mengikuti pelatihan ini sebanyak 40 peserta yang terdiri dari dosen dan mahasiswa. Para peserta mengikuti acara ini sejak awal hingga acara selesai. Berikut adalah dokumentasi foto kegiatan pengabdian kepada masyarakat ini.

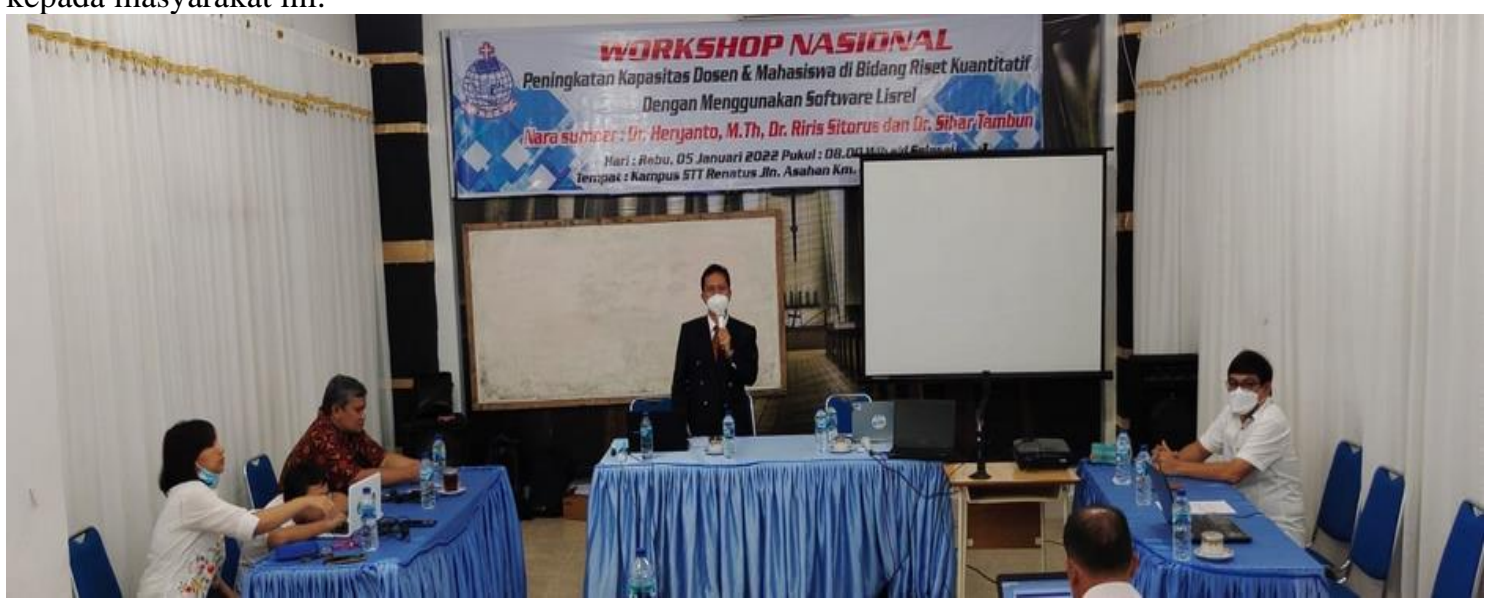

Gambar 1. Sambutan dan Pembukaan Dari Ketua STT Renatus

Gambar 1 adalah foto kegiatan saat ketua STT Renatus Pematang Siantar memberikan sambutan sekaligus membuka acara. Beliau menyampaikan rasa terimasih kepada panitia dan narasumber atas terlaksananya acara ini. Beliau juga menyampaikan tentang kinerja penelitian para dosen dan mahasiswa khususnya dalam hal publikasi artikel ilmiah yang masih kurang. Belum banyak dosen yang produktivitas penelitiannya rutin dan masih banyak dosen yang belum menembus jurnal-jurnal nasional dan internasional bereputasi. Pelatihan ini sangat dibutuhkan sebagai upaya untuk meningkatkan kualitas dan produktivitas penelitian para dosen dan mahasiswa. Kegiatan pelatihan yang dilakukan ini diharapkan bisa bekelanjutan dimasa yang akan datang dengan topik-topik yang lain yang relevan untuk peningkatan kemampuan para dosen dan mahasiswa di bidang penelitian.

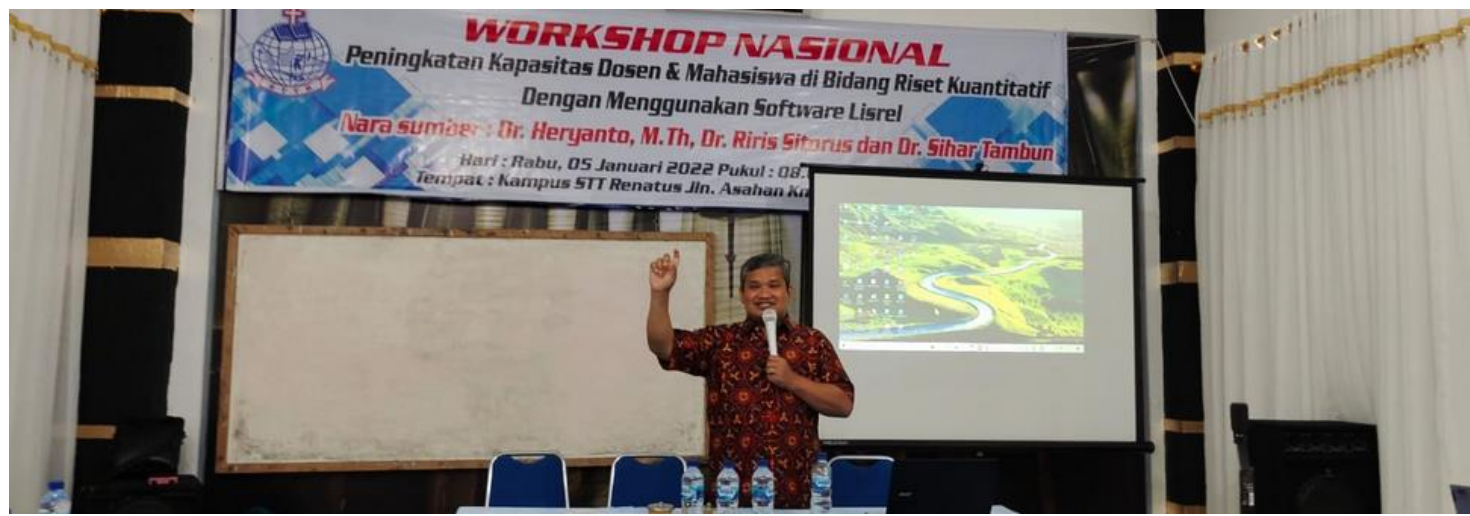

Gambar 2. Pemaparan Materi Pelatihan dari Narasumber

Gambar 2 adalah foto kegiatan pada saat narasumber memberikan penjelasan secara teori tentang software lisrel dan cara penggunaanya. Kemudian dilanjutkan dengan praktek. Praktek mulai dari install software, cara input data, cara pengujian kualitas data dengan confirmatory factor analysis dan goodness of fit, serta praktek pengujian hipotesis. 


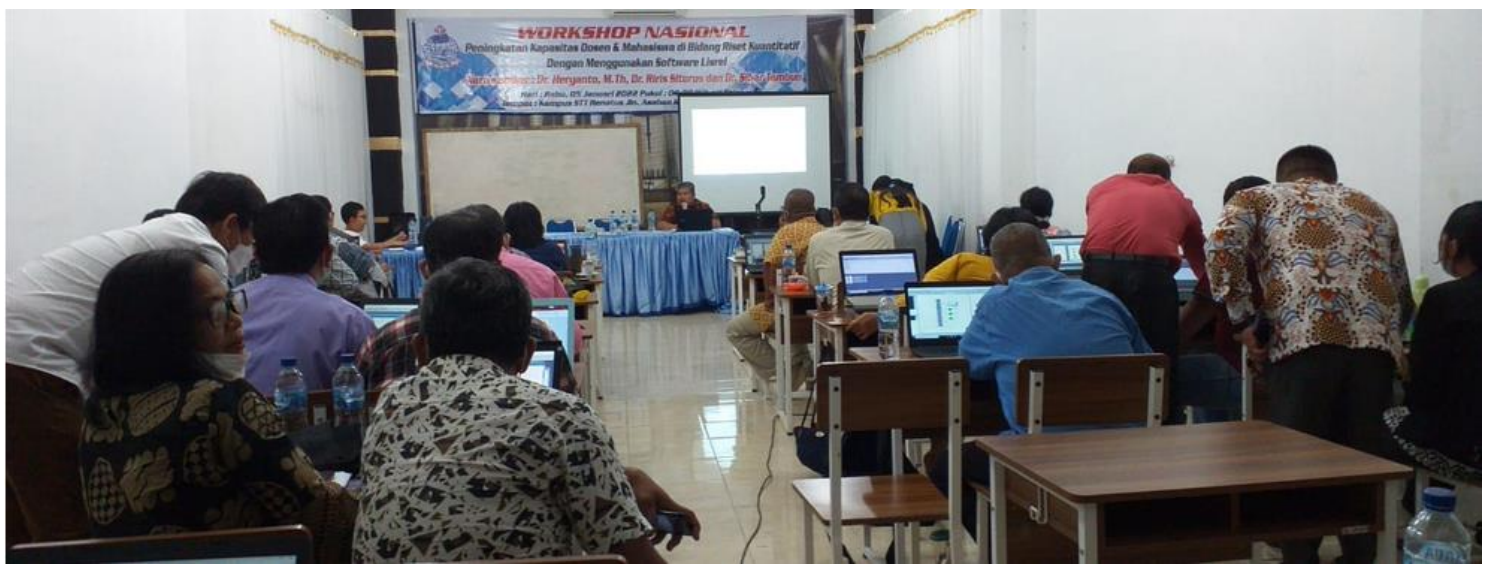

Gambar 3. Foto Para Peserta Sedang Mengikuti Pelatihan

Gambar 3 adalah foto kegiatan acara yang memperlihatkan para peserta sangat serius mengikuti penjelasan teoritis. Setelah penjelasan teoritis selesai dilanjutkan dengan sesi praktek. Pada sesi praktek para peserta sangat antusias saling mengajari satu dengan yang lain. Hal ini membuat suasana pelatihan sangat hidup dan semuanya bersemangat untuk berpraktek. Narasumber menjawab semua kesulitan yang dialami para peserta. Kegiatan ini telah memberikan tambahan kemampuan bagi para peserta.

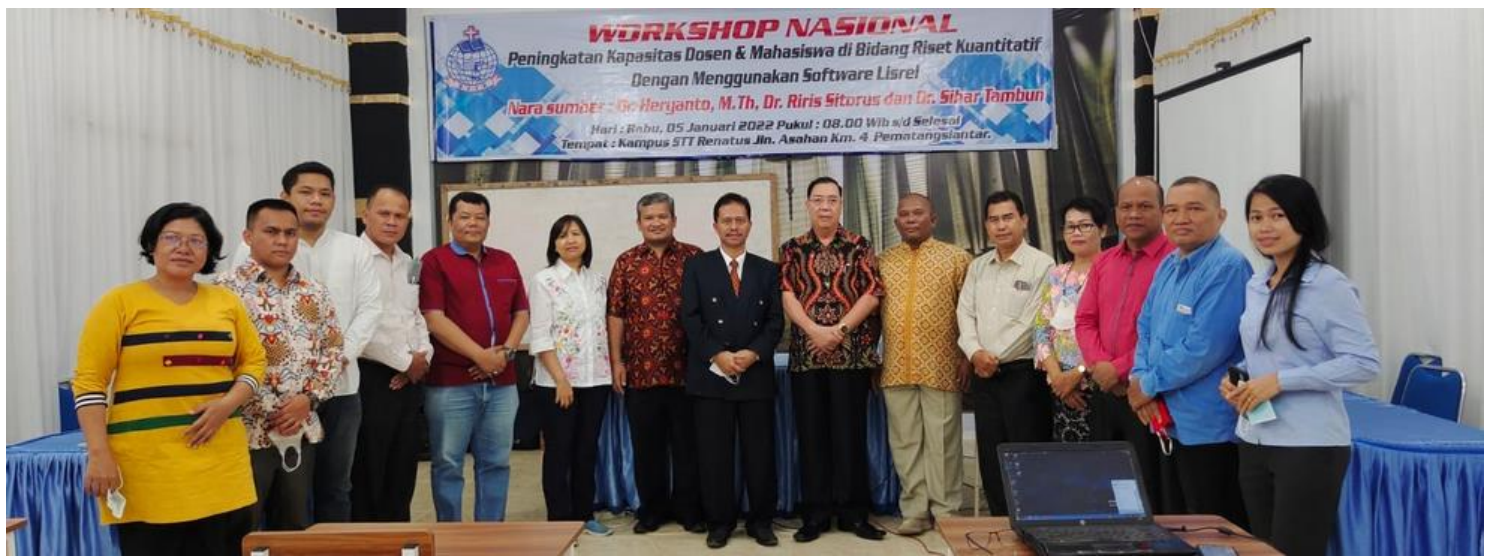

Gambar 4. Foto Bersama Pimpinan dan Dosen STT Renatus

Gambar 4 adalah foto bersama pimpinan dan beberapa dosen STT Renatus Pematang Siantar. Semoga kebersamaan ini dapat menumbuhkan semangat baru untuk meningkatkan kualitas penelitian demi kemanjuan STT Renatus Pematang Siantar.

Hasil evaluasi kegiatan dilakukan dengan membandingkan score pretest dan posttest para peserta pelatihan. Score ini didapatkan dari jawaban para peserta atas 10 pertanyaan yang telah diberikan diawal dan diakhir acara. Pertanyaan diberikan terkait dengan pemahaman para peserta tentang penggunaan software lisrel untuk mengolah data penelitian. Setiap satu pertanyaan memiliki bobot yang sama yaitu masing-masing $10 \%$. Total score < 50 kurang, score 50-70 cukup, dan score > 70 sudah baik. Berikut adalah scorenya:

Tabel 1. Score Pretest dan Posttest Penguasaan Software Lisrel

\begin{tabular}{|c|l|c|c|}
\hline No. & \multicolumn{1}{|c|}{ Penguasaan Software Lisrel } & Pretest & Posttest \\
\hline 1 & Pemahaman dan penguasaan software lisrel sudah baik & - & $30(75 \%)$ \\
\hline 2 & Pemahaman dan penguasaan software lisrel cukup & $2(5 \%)$ & $10(25 \%)$ \\
\hline 3 & Pemahaman dan penguasaan software lisrel kurang & $38(95 \%)$ & - \\
\hline \multicolumn{2}{|c|}{ Jumlah peserta } & $40(100 \%)$ & $40(100 \%)$ \\
\hline
\end{tabular}

Dari tabel 1 dapat dilihat bahwa terdapat peningkatan kemampuan menggunakan software lisrel sebelum pelatihan dilakukan dan setelah pelatihan dilakukan. Sebelum pelatihan dilakukan masih belum ada peserta yang memahami dengan baik penulisan artikel ilmiah. Selesai pelatihan, ada sebanyak 30 peserta (75\%) sudah memahami dan menguasai dengan baik penggunaan software lisrel. Hal ini menunjukkan bahwa pelatihan ini berdampak besar terhadap peningkatan kemampuan para peserta. Mayoritas para peserta sudah memahami pemanfaatan software lisrel untuk proses input data, untuk uji confirmatory factor analysis, untuk uji goodness of fit, untuk uji hipotesis direct effect dan untuk uji hipotesis indirect effect. Para peserta juga sudah dibekali dengan kemampuan menginterpretasikan hasil pengolahan data. 
Diharapkan para peserta dapat terus belajar dan mengembangkan kemampuan pemanfaatan software lisrel agar semakin terlatih dan dapat mendukung kinerja penelitian para peserta.

\section{PENUTUP}

Pelatihan ini berdampak besar pada peningkatan kemampuan para dosen dan mahasiswa dalam pemanfaatan software lisrel untuk mengolah data penelitian kuantitatif dengan menggunakan kuisioner. Mayoritas peserta sudah menguasai teknik penggunaan lisrel, meliputi cara input data, cara uji confirmatory factor analysis dan kriterianya, cara uji goodness of fit dan kriterianya, cara pengujian hipotesis baik yang pengujian direct effect maupun pengujian indirect effect. Para peserta juga sudah dibekali dengan kemampuan membaca dan menginterpretasikan hasil pengolahan data. Dengan penguasaan skill ini para peserta sudah mampu secara mandiri mengolah data penelitian kuantitatif yang berasal dari penyebaran kuisioner.

\section{Ucapan Terimakasih}

Terimakasih kami ucapkan kepada bapak ketua STT Renatus Pematang Siantar atas ijin dan kerjasama pelaksanaan program pengabdian kepada masyarakat ini. Terimakasih juga kepada para dosen dan panitai, serta semua peserta yang telah mendukung acara ini sehingga bisa berjalan dengan sangat baik. Semoga acara ini menjadi berkat untuk kita semua.

\section{E. DAFTAR PUSTAKA}

Bliss, E. S., Wong, R. H. X., Howe, P. R. C., \& Mills, D. E. (2021). Benefits of exercise training on cerebrovascular and cognitive function in ageing. Journal of Cerebral Blood Flow and Metabolism. https://doi.org/10.1177/0271678X20957807

Burn, M., Tully, L. A., Jiang, Y., Piotrowska, P. J., Collins, D. A. J., Sargeant, K., ... Dadds, M. R. (2019). Evaluating Practitioner Training to Improve Competencies and Organizational Practices for Engaging Fathers in Parenting Interventions. Child Psychiatry and Human Development. https://doi.org/10.1007/s10578-018-0836-2

Molenaar, P. C. M. (2019). Review of Multivariate Analysis with LISREL. Structural Equation Modeling: A Multidisciplinary Journal. https://doi.org/10.1080/10705511.2019.1566002

Ondé, D., \& Alvarado, J. M. (2018). Scale validation conducting confirmatory factor analysis: A Monte Carlo simulation study with LISREL. Frontiers in Psychology. https://doi.org/10.3389/fpsyg.2018.00751

Powell, T. C. (2020). Can Quantitative Research Solve Social Problems? Pragmatism and the Ethics of Social Research. Journal of Business Ethics. https://doi.org/10.1007/s10551-019-04196-7

Retnowati, T. H., Mardapi, D., \& Kartowagiran, B. (2018). Kinerja dosen di bidang penelitian dan publikasi ilmiah. Jurnal Akuntabilitas Manajemen Pendidikan. https://doi.org/10.21831/amp.v6i2.21524

Win, H. H., Myint, A. T., \& Cho, M. C. (2020). Analysis on Research Paper Publication Recommendation System with Composition of Papers and Conferences Matrices. International Journal of Scientific Research in Science, Engineering and Technology. https://doi.org/10.32628/ijsrset207330

Ying, J. (2020). The Importance of the Discussion Method in the Undergraduate Business Classroom. Humanistic Management Journal. https://doi.org/10.1007/s41463-020-00099-2 